\title{
EFFECTS OF ASYMMETRY ON EX ANTE CORRUPTION AT AUCTIONS
}

\author{
ŞEVKET ALPER KOÇ \\ Kocaeli University
}

\begin{abstract}
I study an auction in which bidders can bribe the auctioneer before they bid and before they know the identity of the winner, with the auctioneer lowering the winner's bid if the winner was the one who paid the bribe. In equilibrium, only bidders with valuations higher than some critical value pay the bribe. Corruption has no effect on either efficiency or the bidders' expected payoffs when the bidders are symmetric, but may improve efficiency when bidders are symmetric and the required bribe is sufficiently high. Ex ante bribery might be more profitable for the auctioneer than ex post bribery, in which a bribe is solicited from the winner after bids are submitted.
\end{abstract}

Key words: bribery, asymmetric auctions, auctioneer.

\section{ASIMETRININ AÇIK ARTIRMALARDAKİ EX ANTE RÜŞVETE ETKILLERI}

\section{ÖZET}

Bu çalışma mal sahibinin aracısı olan müzayedecinin tüm teklif verenlere yaklaşıp onlara, e $\breve{g} e r$ bir miktar rüşvet verirlerse ve en yüksek teklifi verirlerse tekliflerini değiştirip sadece ikinci en yüksek teklifi ödemelerini söz verdiği bir açık artırma üzerinedir. Dengede, belirli bir miktarın üzerindeki değere sahip teklif verenler rüssveti verecektir ve kendi değerlerini teklif vereceklerdir. Rüsvet ve ahlaki bozulma açık artırmanın verimliliği ve teklif verenlerin biçtikleri değerin dă̆ılımı simetrik iken beklenen kazançları üzerine bir etki yaratmamıştır. Ancak biçilen de ğerlerin dağılımı asimetrik iken ex ante rüssvet ex post rüşvete göre müzayedeci için daha karlı olabilmektedir.

Anahtar kelimeler: rüşvet, asimetrik ihaleler, müzayedeci.

In many cases, but not all, a sealed-bid auction has an auctioneer. Sometimes the auctioneer is a third party in the transaction, and sometimes it is an individual who works for the firm awarding the prize and who is given the task of collecting the bids from the bidders. The existence of an agent coming between the seller and the bidders raises the possibility of corruption in two ways. First, the auctioneer could look at the submitted bids and then solicit a bribe from the winner after the bids are submitted in exchange for changing the bid in a way that is favorable to the winner. In a standard high-bid auction,

* I am indebted to William Neilson, Thomas Jeitschko, Çağatay Koç, and Wolfgang Köhler for their helpful comments.

** Şevket Alper Koç is an Assistant Professor in the Department Economics at Kocaeli University, 41380. Izmit, Kocaeli, Turkey. E-mail: alperkoc@kou.edu.tr 
this would entail soliciting a bribe in exchange for lowering the winner's bid to the second-highest bid. Second, the auctioneer could solicit bribes from the bidders before the bids are submitted, in exchange for a promise to reduce the bidder's bid should that bidder be the winner. Several existing papers address ex post bribery, which occurs after all of the bids are submitted. Lengwiler and Wolfstetter (2000) analyze auctions in which the winning bidder can bribe the auctioneer to change the bid after the auction has ended. Their results are similar to ours, although the results depend on the possibility of the corruption being detected and punished. Menezes and Monteiro (2006) consider a scenario in which there are two bidders and the auctioneer approaches one of them to solicit a bribe in return for changing the bid. The auctioneer can approach either the winner or the loser. Burguet and Perry (2002) study an auction in which one bidder is honest but one is corrupt. Burguet and Che (2002) and Celentani and Ganuza (2002) study a procurement auction in which the awarding of the contract is based on both the price and the quality of the project, and a corrupt auctioneer can manipulate the quality component in exchange for a bribe.

Esö and Schummer (2004) examine ex ante bribery between the bidders, not the bidders and the auctioneer. They analyze whether a two-bidder, second price auction for a single good is immune to a simple form of collusion where one bidder may bribe the other to commit to staying away from the auction (i.e., submit a bid of zero).

This paper analyzes ex ante bribery between the bidders and the auctioneer that occurs before the bids are submitted. ${ }^{(1)}$ I chose to focus on ex ante bribery for several reasons. First, one can find instances of ex ante bribery in real-world auctions, and so its analysis is relevant. Second, one can imagine scenarios in which the auctioneer has an opportunity to change the winner's bid after all of the bids have been submitted, but not the opportunity to approach the highest bidder and solicit a bribe in return for changing the bid, in which case ex ante bribery is possible, but ex post bribery is not. This may be the case where the auctioneer has to open the envelopes and decide who wins the auction shortly after the bids are submitted. So, in these cases a corrupt auctioneer should approach the bidders and solicit bribe before the bids are submitted. Finally, ex post bribery has already been analyzed. Even so, it is a worthwhile exercise to compare the two forms of bribery.

This is not simply an academic exercise, because ex ante bribery has been documented in actual auctions. In their bids for corporate waste-disposal contracts in New York City, mafia families would sometimes pay bribes for an "undertaker's look" at the bids of the other bidders before making their own bids (Cowan and Century, 2002: 223-231). In 1997, a Covington, Kentucky, developer was shown the bids of two competing developers for a $\$ 37$ million dollar courthouse construction project (Crowley, 2000). In Chelsea, Massachusetts, in the 1980s, the city's auctioneer was accused of accepting bribes to rig auctions in favor of certain bidders, one time serving as a bidder's agent in an auction he was running (Murphy, 1993). Lengwiler and Wolfstetter (2000) relay two examples involving German firms which they claim provide evidence of ex post bribery, but I think provide better evidence of ex ante bribery. In one incident, one bidder illegally acquired the application documents of a rival bidder for the Berlin airport construction contract, and in a second incident, Siemens was barred from bidding in public procurement auctions in Singapore for five years because they had bribed an official for information about rival bids. Since the rival bids could be obtained and used before the bribers made their own bids, these could be instances of ex ante bribery.

Finally, I have also been told that auctioneers solicit ex ante bribes for some types of procurement contracts in Turkey. The contracts are auctioned using a standard first-price, sealed-bid auction, with 
the bidder who offers to supply the good at the lowest price winning the auction and supplying the good at that price. Before the bidding starts, the corrupt auctioneer approaches certain bidders with whom he has worked before, and offers to raise their bids to the second-best bid if they win in exchange for a bribe. ${ }^{(2)}$

The key feature of these examples is that in every case the bidders pay bribes to secure some action that will allow them to earn higher profits if they win, but the bribe is paid before the bidders know whether or not they will win. I construct a model to fit this feature. The auction is a first-price, sealed bid auction with no reserve price, with the highest bidder winning. Before the bidding, the auctioneer announces the size of the bribe he demands. As many bidders as want to can pay the bribe, and if a bidder who pays the bribe submits the highest bid, the auctioneer lowers the winning bid to the secondhighest bid. ${ }^{(3)}$ The high bidder then wins the auction and pays the second-highest bid.

I show that in the case where all bidders draw their valuations independently from a single distribution, bidders who have valuations higher than some critical value pay a bribe to the auctioneer, and bidders with low valuations do not. Bidders who pay the bribe bid their own valuations as if they were in a second-price, sealed-bid auction, and bidders who do not pay the bribe bid according to the standard equilibrium bid function from the first-price auction. The resulting bid function for all bidders is increasing, and therefore the bidder with the highest value wins the auction, whether he pays the bribe or not, and the auction is efficient. The bidders' expected equilibrium payoffs are unaffected by corruption. They are neither worse off nor better off in terms of the equilibrium expected payoffs. However, there is a transfer of wealth from the seller to the auctioneer.

Asymmetric auctions, in which bidders draw their valuations from different distributions, are naturally asymmetric (See Maskin and Riley, 2000; Lebrun, 1999; and Fibich et al., 2002; 2004). Consider a particular case in which the strong bidder draws from a distribution that stochastically dominates the one from which the weak bidder draws. Maskin and Riley (2000) show that this can lead the weak bidder to bid more aggressively than the strong bidder, which can lead to an inefficient allocation in which the strong bidder has the higher valuation, but the weak bidder submits the higher bid. If the strong bidder pays a bribe this scenario cannot arise, and I show that if the bribe is sufficiently expensive and valuations are distributed uniformly, bribery improves the expected efficiency of the auction.

I proceed as follows. The next section presents the game and the notation. After that, an examination of the behavior of bidders, determining who pays the bribe and how they bid, is presented. The next section finds that the equilibrium of the game when bidders are ex ante symmetric, and shows that the auction is efficient and that the bribes are a transfer from the seller to the auctioneer. Finally, the analysis expands to asymmetric auctions, exploring efficiency issues. The paper concludes with a comparison of ex ante bribery to ex post bribery.

\section{STRUCTURE OF THE GAME}

The seller of a single good faces $n$ risk neutral potential buyers. The seller has hired an auctioneer to run a sealed-bid, first-price auction, and pays the auctioneer a fixed wage (as opposed to a commission) in exchange for his services. ${ }^{(4)}$ In contrast to the standard first-price auction, the game is supplemented by corruption between the auctioneer and the bidders. The auctioneer approaches each bidder before 
the auction is held and tells him that if he agrees to pay a bribe of $\alpha$, and is the highest bidder, he pays the second-highest bid. If the highest bidder did not pay the bribe, he pays his bid. Bribes are collected from all bidders who agreed to pay, even from losing bidders. Consequently, the game is a three-stage game. In the first stage the auctioneer sets $\alpha$, in the second stage the bidders decide whether to pay $\alpha$ independently and simultaneously, and in the third stage the bidders choose their bids.

Below, the bidders are assumed to be identical ex ante, drawing valuations $v_{1}, \ldots, v_{n}$ independently from the distribution $F$ with support $[0,1]$ as in the standard symmetric private values model. The section follows that the auction is made asymmetric, allowing bidders to draw valuations from different distributions. I assume throughout that the value of the object to the seller is zero and the reserve price is zero. There is no entry fee, making it optimal for all bidders to bid. The seller is passive in this game and we ignore issues related to the detection and punishment of corruption.

I restrict attention to equilibria that survive weak dominance. This rules out preemptive strategies such as one bidder paying the bribe and bidding above one while the other bidders do not pay the bribe and bid zero.

\section{BIDDER BEHAVIOR}

In this section I analyze the behavior of bidders given the size of the bribe, $\alpha$, set by the auctioneer. Specifically, I characterize the equilibrium of the sub game that follows the auctioneer's choice of $\alpha$. The first task is to find the bids of bidders who do and do not pay the bribe. If a bidder pays the bribe and is the highest bidder, he pays the second highest bid. Therefore, after paying the bribe the bidder essentially participates in a second price auction, and his dominant strategy is to bid his valuation.

Lemma 1: Any bidder who pays the bribe bids his valuation, $v_{i}$.

My main result concerns when bidders pay the bribe and when they do not. The next lemma states that bidders use cutoff strategies, that is, for bidder $i$ there is a valuation $v_{i}^{*}$ such that he pays the bribe when $v_{i} \geq v_{i}^{*}$ and does not pay the bribe when $v_{i}<v_{i}^{*}$.

Lemma 2: In any equilibrium every bidder uses a cutoff strategy.

Proof: See the appendix.

\section{SYMMETRIC AUCTIONS}

In this section it is assumed that bidders are ex ante symmetric, so that their valuations are drawn independently from a single distribution $F$. Given a value of $\alpha$ chosen by the auctioneer, Lemma 2 states that each bidder uses a cutoff strategy, paying the bribe if their valuations are above the cutoff and declining to pay the bribe when their values are below the cutoff. Since the auction is symmetric, it makes sense to look at a symmetric equilibrium in which all bidders use the same cutoff strategy.

If a bidder does not pay the bribe, he must pay his own bid if he wins. Consequently, and for the standard reasons, he bids less than his valuation. How much less depends on the behavior of other bidders. In a symmetric equilibrium, if a bidder with valuation $v_{i}$ declines the bribe, all bidders with lower valuations also decline the bribe. Let $b_{i 1}\left(v_{i}\right)$ denote the equilibrium bid function in a standard 
first-price sealed bid auction without bribery, and for the special case of an ex ante symmetric auction $b_{i 1}$ is given by

$$
b_{1}\left(v_{i}\right)=v_{i}-\frac{1}{F^{n-1}\left(v_{i}\right)} \int_{0}^{v_{i}} F^{n-1}(y) d y .
$$

Lemma 3: If bidder $i$ does not pay the bribe and all the bidders with valuations below $v_{i}$ do not pay the bribe, bidder $i$ bids according to the function $b_{i 1}\left(v_{i}\right)$.

Proof: Let $b(v)$ denote the equilibrium bid function for bidders who choose not to pay the bribe. For the standard reasons, $b$ is assumed to be increasing. By Lemma 1, all bidders who do pay the bribe bid their valuations, and $v \geq b(v)$ for all $v$. If bidder $i$ does not pay the bribe, and all bidders with valuations below $v_{i}$ also do not pay the bribe, bidder $i$ only wins when his is the highest valuation. The theory of first price auctions then implies that, conditional on his own valuation being the highest, bidder $i$ 's optimal bid is then $b_{i 1}\left(v_{i}\right)$.

Lemmas 1 and 2 state that in a general, possibly asymmetric auction bidders use a cutoff rule for deciding when to pay the bribe and bid their valuations if they do pay the bribe. Lemma 3 states that if the auction is symmetric and if there is a symmetric equilibrium, bidders bid according to the standard first-price auction bid function when they do not pay the bribe. The next theorem shows that a symmetric equilibrium exists, and that there is only one symmetric equilibrium of the subgame.

Theorem 1: Suppose that valuations are drawn independently from the distribution $F$. Given the amount of the bribe $\alpha$, there exists a unique symmetric Bayesian-Nash equilibrium in which bidders with values in $\left[0, v^{*}\right)$ do not pay the bribe and bidders with values in $\left[v^{*}, 1\right]$ do pay the bribe, where $v^{*}$ solves

$$
\int_{0}^{v^{*}}\left[b_{1}\left(v^{*}\right)-b_{1}(v)\right] d F^{n-1}(v)=\alpha
$$

and $b_{1}$ is the standard first-price auction bid function.

Proof: See the appendix.

Let $v^{*}$ denote the threshold valuation such that a bidder with valuation $v^{*}$ is indifferent about paying the bribe, and, by hypothesis, all bidders with valuations above $v^{*}$ pay the bribe and all those with valuations below $v^{*}$ do not. A bidder with valuation $v^{*}$ who pays the bribe only beats bidders with lower valuations, and earns an expected surplus of

$\int_{0}^{v^{*}}\left[v^{*}-b_{1}(v)\right] d F^{n-1}(v)-\alpha$. A bidder with valuation $v^{*}$ who does not pay the bribe earns an expected surplus of $\int_{0}^{v^{*}}\left[v^{*}-b_{1}\left(v^{*}\right)\right] d F^{n-1}(v)$. The fact that the bidder is indifferent reduces to $\int_{0}^{v^{*}}\left[b_{1}\left(v^{*}\right)-b_{1}(v)\right] d F^{n-1}(v)=\alpha$, which is simply expression (2). Thus, given $\alpha$, the cutoff value $v^{*}$

must satisfy (2). 
A second interpretation of $v^{*}$ arises from noticing that the first price bid function, $b_{1}(v)$, is the expected second-highest valuation conditional on $v$ being the highest valuation. Since

$$
b_{1}\left(v^{*}\right)=\frac{\int_{0}^{v^{*}} v d F^{n-1}(v)}{F^{n-1}\left(v^{*}\right)},
$$

equation (2) can be re-written as

$$
\int_{0}^{v^{*}}\left[v-b_{1}(v)\right] d F^{n-1}(v)=\alpha
$$

Equation (4) has a straightforward interpretation. Suppose that a bidder with valuation $v_{1}$ pays the bribe, bids $v_{1}$, and wins the auction, and that the second-highest bidder has valuation $v$. If the secondhighest bidder paid the bribe, he bids $v$, and the winning bidder's surplus is $v_{1}-v$. If the second-highest bidder did not pay the bribe, he bids $b_{1}(v)$, and the winning bidder's surplus is $v_{1}-b_{1}(v)>v_{1}-v$. There is a clear benefit when the second highest bidder does not pay the bribe. Now, note that revenue equivalence implies that, without corruption, a bidder's expected surplus from a second-price auction is identical to his expected surplus from a first-price auction. So, his expected surplus (gross of the bribe) is the same if he and everyone else pay the bribe or if he and everyone else do not pay the bribe. The benefit from the bribe, then, must come from the additional surplus from facing people who do not pay the bribe. This additional surplus is $\int_{0}^{v^{*}}\left[v-b_{1}(v)\right] d F^{n-1}(v)$, which is the quantity on the lefthand side of (4). The equation says that enough people must choose not to pay the bribe so that the additional surplus from paying the bribe exactly offsets the cost of the bribe.

Figure 1 shows this graphically. Bidders who pay the bribe bid according to the second-price auction bid function $b_{2}(v)=v$, and bidders who do not pay the bribe bid according to the first-price auction bid function $b_{1}(v)$. The left-hand term in equation (4) is the weighted area between these two functions over the interval $\left[0, v^{*}\right)$, which is shown by the shaded area in the figure. ${ }^{(5)}$ The weights are not shown in the graph, but they are given by the distribution function $F^{n-1}(v)$.

Figure 1

\section{Representation of the Amount of Bribe}

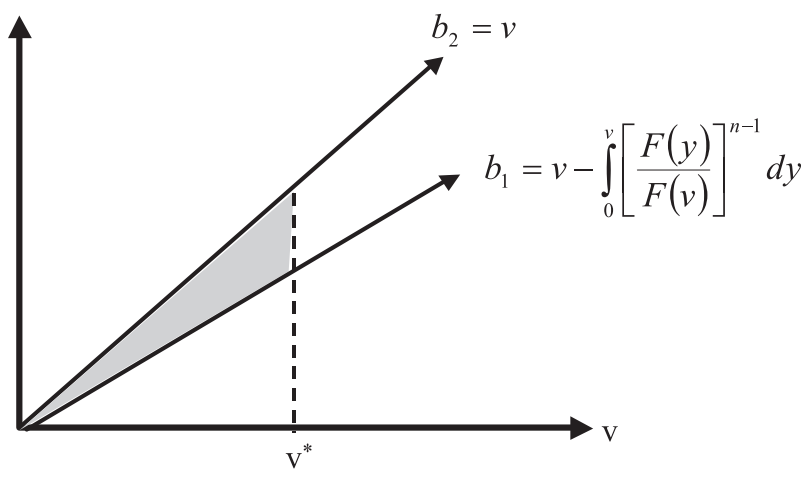


Informally, a bidder who draws a value less than $v^{*}$ prefers not to pay the bribe because if he pays the bribe his surplus rises only by a fraction of the shaded region in Figure 1, but he must pay an amount equal to the entire shaded region, so the bribe makes him worse off. A bidder who draws a value higher than $v^{*}$ prefers to pay the bribe because the extra surplus in the shaded region is exactly offset by the bribe, but if he does not pay the bribe he loses the auction to people with valuations lower than his. Put another way, if a bidder with a valuation higher than $v^{*}$ does not pay the bribe, he loses more than it costs to pay the bribe.

The uniqueness of $v^{*}$ for a given $\alpha$, together with the fact that the left-hand side of (2) is strictly increasing in $v^{*}$, implies that there exists a strictly increasing function $v^{*}(\alpha)$ that describes the equilibrium threshold valuation as a function of the bribe. Given $\alpha$, the equilibrium bid function can then be written

$$
b(v)=\left\{\begin{array}{ccc}
b_{1}(v) & & v<v^{*} \\
v & \text { if } & \\
v & & v \geq v^{*}
\end{array}\right.
$$

where $b_{1}(v)$ is the standard first-price auction bid function, which is increasing. Since $b_{1}\left(v^{*}\right)<v^{*}$, the bid function $b(v)$ is increasing. Furthermore, a bidder with a valuation of 0 does not pay the bribe and earns zero expected surplus. Consequently, the Revenue Equivalence Theorem (Myerson, 1981) implies the following corollary.

Corollary 1: The auction with bribery is efficient, and any bribes paid are a transfer from the seller to the auctioneer.

Corollary 1 has two parts. First, the auction with bribery is efficient, because the prize is awarded to the bidder with the highest valuation. This follows from the fact that the equilibrium bid function is increasing, and the fact that the bidder with the highest valuation wins suggests that no losing bidder will complain to an outside authority about the bribery since that bidder would not have won the auction in the absence of bribery, either. The efficiency result relies heavily on the assumption that all bidders have the chance to pay the bribe, though. To see why, suppose that only bidder 1 can pay the bribe. If he pays the bribe he bids his valuation, but all of the other bidders bid below their valuations. If they use the bid function $B$, it is possible that for some $i \neq 1, v_{i}>v_{1}>B\left(v_{i}\right)$, in which case the prize is inefficiently awarded to the only bidder who paid the bribe.

The corollary also states that bribes are transfers from the seller to the auctioneer. Put another way, the existence of a corrupt auctioneer has no impact on the expected surpluses of the bidders. This last result can be seen easily with the help of Figure 1 . The threshold valuation $v^{*}$ just equates the size of the bribe with the advantages from participating in a second-price auction against bidders who are bidding in a first-price auction. Bidders who pay the bribe, then, just make back the bribe in expectation, and so paying the bribe has no impact on their expected surplus. ${ }^{(6)}$ Since the bidders' expected surplus is unchanged, the usual amount of expected revenue is shared by the auctioneer and the seller, with the auctioneer's payoffs coming from bribes. The seller's expected revenue, therefore, is reduced by the expected bribe payments. 
Now let us turn our attention to the decision facing the auctioneer. In the first period the auctioneer chooses the size of the bribe $\alpha$ that a bidder must pay in order to learn the second highest bid if he is the highest bidder. So, the auctioneer aims to maximize his expected revenue by choosing $\alpha$. By Theorem 1 , though, for any given $\alpha$ there is a unique threshold valuation $v^{*}$ such that bidders with valuations above $v^{*}$ pay the bribe and those with valuations below $v^{*}$ do not. Because of the uniqueness, choosing $\alpha$ is the same as choosing $v^{*}$. Let

$$
\alpha\left(v^{*}\right)=\int_{0}^{v^{*}}\left[b_{1}\left(v^{*}\right)-b_{1}(v)\right] d F^{n-1}(v) .
$$

The auctioneer's expected revenue is given by

$$
R\left(v^{*}\right)=n\left(1-F\left(v^{*}\right)\right) \alpha\left(v^{*}\right)
$$

where $n$ is the number of bidders, $1-F\left(v^{*}\right)$ is the probability that a given bidder pays the bribe, and $\alpha\left(v^{*}\right)$ is the size of the bribe. Since choosing $\alpha$ is the same as choosing $v^{*}$, the auctioneer's problem is to choose $v^{*}$ to maximize expected revenue.

It is apparent from (6) that $\alpha\left(v^{*}\right)$ is continuous since it is differentiable. As long as the distribution $F$ of bidders' valuations is continuous, it follows that $R\left(v^{*}\right)$ is continuous, which establishes the next result.

Corollary 2: There exists an $\alpha$ that maximizes expected revenue, and the corresponding $v^{* * *}$ lies in the interval $(0,1)$.

Proof. The problem of choosing $\alpha$ to maximize revenue is isomorphic to the problem of choosing $v^{*} \in[0,1]$ to maximize $R\left(v^{*}\right)$. Since the function is continuous on [0,1], it attains a maximum. When $\alpha=0$, it follows that $v^{*}=0$, which implies that $R(0)=0$. Also, when $v^{*}=1$, it follows that $1-F\left(v^{*}\right)=0$, which implies that $R(1)=0$. Finally, since $R\left(v^{*}\right)>0$ when $v \in(0,1)$, the result holds.

I close this section with two examples. First, suppose that valuations are distributed uniformly on $[0,1]$. Then the equilibrium first-price auction bid function is $b_{1}(v)=(n-1) v / n$, and from (6) we get $\alpha(v)=v^{n} / n^{2}(n-1)$. Substituting into (7) and maximizing with respect to $v$ yields $v^{* *}=n /(n+1)$. Interestingly, this is the expected value of the highest of the $n$ valuations. So, only bidders with very high valuations pay the bribe.

For the second example, suppose that valuations are drawn from the power function distribution $F(v)=v^{2}$ on $[0,1]$, so that the density function is $f(v)=2 v$. The equilibrium first-price auction bid function is $b_{1}(v)=(2 n-2) v /(2 n-1)$, and $\alpha(v)=(2 n-2) v^{3} /(6 n-3)$. The auctioneer's expected revenue can then be written $R(v)=k\left(v^{3}-v^{5}\right)$, where $k$ is a constant that depends on $n$. The optimal threshold value is then $v^{* *}=0.6^{1 / 2}$, which does not depend on the number of bidders. With this distribution, any bidder with a value greater than about 0.775 pays the bribe, regardless of the number of competitors.

\section{ASYMMETRIC AUCTIONS}

In asymmetric auctions bidders draw their valuations independently from different distributions. These can lead to inefficiencies. To see how, suppose that there is a weak bidder who draws valuations from $F_{W}$ and a strong bidder who draws valuations from $F_{S}$, with $F_{S}(v) \leq F_{W}(v)$ so that the strong 
distribution first-order stochastically dominates the weak one. Under certain conditions the weak bidder bids more aggressively than the strong bidder. Letting $b_{W}$ and $b_{S}$ be the weak and strong bid functions, respectively, it may be the case that $b_{W}(v) \geq b_{S}(v)$ for all $v$ in the intersection of the supports of $F_{W}$ and $F_{S}$, so that the weak bidder bids more than the strong bidder does for the same valuation. This can lead to an inefficient allocation if valuations $v_{W}$ and $v_{S}$ occur such that $v_{S}>v_{W}$ but $b_{W}\left(v_{W}\right)>b_{S}\left(v_{S}\right)$, sothat thestrongestbidderhasahighervaluationbutplacesalowerbidthan the weakbidder. ${ }^{(7)}$ An efficient auction would award the prize to the strong bidder in this case. If the strongest bidder pays a bribe to the auctioneer, however, he then bids his valuation and the above inefficiency cannot occur. Perhaps, then, bribes improve the efficiency of an asymmetric auction. I explore that possibility in this section.

To make this concrete, assume that the two bidders draw their valuations asymmetrically from $F_{W}$ and $F_{S}$ and they use equilibrium bid functions $b_{W}$ and $b_{S}$, respectively, when bribery is not allowed. Further assume that $b_{W}(v) \geq b_{S}(v)$, so that without bribery, the only inefficient allocations award the prize to the weak bidder. The supports of $F_{W}$ and $F_{S}$ are $\left[0, \bar{v}_{W}\right]$ and $\left[0, \bar{v}_{S}\right]$, respectively. The expected efficiency loss is given by the following expression, where the superscript "NB" signifies no bribery.

$$
L^{N B}=\int_{0}^{\bar{v}_{S}} \int_{b_{W}^{-1}\left(b_{S}\left(v_{S}\right)\right)}^{v_{S}}\left(v_{S}-v_{W}\right) d F_{W}\left(v_{W}\right) d F_{S}\left(v_{S}\right) .
$$

To understand this expression, begin with a valuation $v_{S}$ for the strong bidder. The inner integral identifies cases in which the weak bidder's valuation $v_{W}$ is such that $b_{W}{ }^{-1}\left(b_{S}\left(v_{S}\right)\right) \leq v_{W} \leq v_{S}$. Applying the weak bid function $b_{W}$ to both sides of the first inequality yields $b_{S}\left(v_{S}\right) \leq b_{W}\left(v_{W}\right)$, and so the inner integral identifies cases in which the weak bidder has a lower valuation but bids higher than the strong bidder. The outer integral takes the expectation over all possible values of $v_{S}$.

Now suppose that only the strong bidder is allowed to pay the bribe. ${ }^{(8)}$ By Lemma 3 he uses a cutoff strategy, and let $v_{S}{ }^{*}$ be the smallest valuation for which he pays a bribe. The expected efficiency loss changes in three ways. First, the weak bidder can no longer outbid the strong bidder when $v_{S} \geq v_{S}^{*}$, reducing the expected efficiency loss. Second, the bid functions change, which affects the probability that a low-valuation bidder outbids a high-valuation one. Third, if $v_{S}^{*}<\bar{v}_{W}$ cases can arise in which the strong bidder has the lower valuation, but outbids the weak bidder.

To explore the impact on expected efficiency further I look specifically at cases in which the weak bidder's valuations are distributed uniformly on [0,1], and the strong bidder's valuations are distributed uniformly on $\left[0, \bar{v}_{S}\right]$ with $\bar{v}_{S}>1$, and $v_{S}^{*} \geq \bar{v}_{W}$. In the absence of bribery, the bid functions are given by (see Krishna, 2002)

$$
b_{W}(v)=\frac{1-\sqrt{1-k v^{2}}}{k v}
$$

and

$$
b_{S}(v)=\frac{\sqrt{1+k v^{2}}-1}{k v}
$$

where $k=1-1 / \bar{v}_{S}$. Note that when 


$$
\frac{\sqrt{1+k v^{2}}-1}{k v} \leq \frac{v}{2} \leq \frac{1-\sqrt{1-k v^{2}}}{k v}
$$

for all $v \in[0,1]$, with all three terms equal when $k=0$, which occurs when $\bar{v}_{S}=1$.

Now suppose that the strong bidder pays a bribe whenever his valuation is at least $v_{S}{ }^{*}$. As in the symmetric case, he bids his valuation if he pays the bribe. Since $v_{S}^{*} \geq \bar{v}_{W}=1$, the weak bidder can only win the auction when he faces a strong bidder with a valuation less than $v_{S}{ }^{*}$, and so he bids as if he faces an opponent whose valuations are distributed uniformly over $\left[0, v_{S}^{*}\right]$. The resulting equilibrium bid functions are

$$
B_{W}(v)=\frac{1-\sqrt{1-k^{*} v^{2}}}{k^{*} v}
$$

and

$$
B_{S}(v)=\left\{\begin{array}{cccc}
\frac{\sqrt{1+k^{*} v^{2}}-1}{k^{*} v} & & v<v_{S}{ }^{*} \\
v & \text { if } & \\
& & v \geq v_{S}{ }^{*}
\end{array}\right.
$$

where $k^{*}=1-1 / v_{S}^{*}$. Since I have assumed that $v_{S}^{*} \geq \bar{v}_{W}$, inefficient allocations can only arise when $v_{S}<v_{S}{ }^{*}$, and the expected efficiency loss function for the bribery case is given by

$$
L^{B}\left(v_{S}^{*}\right)=\int_{0}^{v_{S}^{*}} \int_{B_{W}^{-1}\left(B_{S}\left(v_{S}\right)\right)}^{v_{S}}\left(v_{S}-v_{W}\right) d F_{W}\left(v_{W}\right) d F_{S}\left(v_{S}\right) .
$$

The differences between $L^{B}$ in (14) and $L^{N B}$ in (8) are that the upper limit for the first integral falls from $\bar{v}_{S}$ in (8) to $v_{S}{ }^{*}$ in (14) and the bid functions change from $b_{W}$ and $b_{S}$ in (8) to $B_{W}$ and $B_{S}$, respectively, in (14).

Theorem 2. Suppose that the weak and strong bidders draw their valuations from the uniform distributions over $[0,1]$ and $\left[0, \bar{v}_{S}\right]$, respectively. If $1 \leq v_{S}{ }^{*}<\bar{v}_{S}$, then bribery increases the expected efficiency of the auction, that is, $L^{B}<L^{N B}$.

Proof. First note that $L^{B}\left(\bar{v}_{S}\right)=L^{N B}$, since the strong bidder never pays the bribe when the threshold $v_{S}^{*}$, matches the upper limit of the support of the strong distribution. Second, it is straightforward to show that $L^{B}\left(\bar{v}_{W}\right)=0$. When $v_{S}^{*}=\bar{v}_{W}$ the weak bidder acts as if he is bidding against an opponent whose valuations are drawn from the same distribution as his own, the uniform distribution on $\left[0, \bar{v}_{W}\right]$. The weak bidder's bid function is then $B_{W}(v)=v / 2$ and the strong bidder's bid function is $B_{S}(v)=v / 2$ on $\left[0, \bar{v}_{W}\right)$ and $B_{S}(v)=v$ on $\left[\bar{v}_{W}, \bar{v}_{S}\right]$. Since the bid functions coincide on $\mathrm{n}\left[0, \bar{v}_{W}\right)$, the outcome is efficient and $L^{B}\left(\bar{v}_{W}\right)=0$. 
The proof is complete if one can establish that $L^{B}\left(v_{S}^{*}\right)$ increases with $v_{S}^{*}$ when $v_{S}^{*} \in\left[\bar{v}_{W}, \bar{v}_{S}\right]$. Differentiating $L^{B}$ with respect to $v_{S}^{*}$ yields

$$
\begin{gathered}
\frac{d L^{B}}{d v_{S}^{*}}=-\int_{0}^{v_{S}^{*}}\left[v_{S}-B_{W}^{-1}\left(B_{S}\left(v_{S}\right)\right)\right] \frac{\partial B_{W}^{-1}\left(B_{S}\left(v_{S}\right)\right)}{\partial v_{S}^{*}} f_{W}\left(B_{W}^{-1}\left(B_{S}\left(v_{S}\right)\right)\right) d F_{S}\left(v_{S}\right) \\
+\int_{B_{W}^{-1}\left(B_{S}\left(v_{S}^{*}\right)\right)}^{v_{S}^{*}}\left(v_{S}^{*}-v_{W}\right) f_{S}\left(v_{S}^{*}\right) d F_{W}\left(v_{W}\right) .
\end{gathered}
$$

The second term on the right-hand side is obviously positive. For the first term, note that $d k^{*} / v_{S}^{*}>0$. When $v<v_{S}^{*}$ differentiating $B_{S}$ with respect to $k^{*}$ yields

$$
\frac{\partial B_{S}}{\partial k^{*}}=-\frac{k^{*} v^{2}+2-2 \sqrt{1+k v^{2}}}{2 k^{2} v \sqrt{1+k v^{2}}}=\frac{B_{S}(v)-v / 2}{k \sqrt{1+k v^{2}}}
$$

which is negative since $B_{S}(v)<v / 2$ when $k^{*}>0$ and $v<v_{S}{ }^{*}$. Similarly,

$$
\frac{\partial B_{W}}{\partial k^{*}}=-\frac{k v^{2}+2 \sqrt{1-k v^{2}}-2}{2 k^{2} v \sqrt{1-k v^{2}}}=\frac{B_{W}(v)-v / 2}{k \sqrt{1-k v^{2}}}
$$

which is positive since $B_{W}(v)>v / 2$ when $k^{*}>0$. Since $B_{W}(v)$ is increasing in $v$, it follows that $B_{W}{ }^{-1}\left(B_{S}\left(v_{S}\right)\right)$ decreases when $k^{*}$ increases, as shown in Figure 2. Consequently, the first term in (15) is positive, and the derivative $d L^{B} / d v_{S}{ }^{*}$ is positive.

Figure 2

Effects of Assmmetry and Corruption on Bids

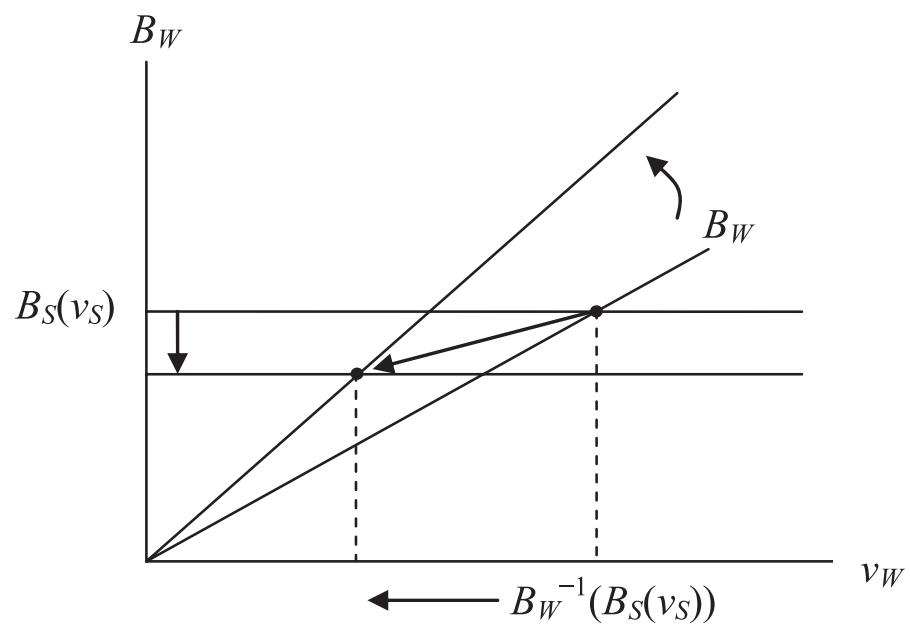


The theorem states that if the bribe is sufficiently expensive that the strong bidder only pays it when his valuation is above the weak bidder's maximal valuation, bribery improves the expected efficiency of the auction. This is not a completely general result for two reasons. First, assumptions are made on the number of bidders and the form of their valuation distributions to allow for explicit equilibrium bid functions. Second, and more importantly, the size of the bribe is assumed to be large enough to make $v_{S}^{*} \geq \bar{v}_{W}$. This assumption is restrictive because it necessarily rules out one source of efficiency loss - the strong bidder paying the bribe and then outbidding a weak bidder with a higher valuation. Without this assumption, though, there may not exist a pure strategy equilibrium, and therefore the theorem only applies to these limited cases. ${ }^{(9)}$

\section{EX ANTE VS. EX POST BRIBERY}

So far in this paper I have restricted attention to situations in which the auctioneer solicits bribes from bidders before the auction begins. This is ex ante bribery. An alternative scenario has the auctioneer soliciting a bribe after the bidding has ended. In particular, the auctioneer could determine who the highest bidder is and solicit a bribe from that bidder to lower the bid to the second-highest bid. This is ex post bribery, and it is analyzed by Lengwiler and Wolfstetter (2000) and Menezes and Monteiro (2006), among others. In this paper I chose to focus on ex ante bribery.

Consider the following ex post bribery game. All $n$ bidders submit their bids in a first-price auction. The auctioneer approaches the highest bidder and, in return for a bribe, reduces the highest bid to just beat that of the second-highest bidder. The highest bidder then wins the auction and pays that bid.

The equilibrium of this game can be found by backward induction. The highest bidder will be willing to pay any bribe that is no larger than the price reduction. Knowing this, the auctioneer sets the bribe equal to the difference between the two highest bids and, since the highest bidder is indifferent, he agrees to pay the bribe. The total payment by the high bidder is his original bid, then, with a portion of it going to the auctioneer and a portion going to the seller. Since the price paid by the winner is the same as in a standard first-price auction, the equilibrium bid function is exactly that of the first-price auction.

The existence of ex post bribery, then, changes neither the bidders' strategies nor their expected payoffs. Ex ante bribery, in contrast, changes the strategies of those who pay the bribe. The relevant issue is which of the two bribery institutions is more profitable for the auctioneer. With ex post bribery, only one bidder pays the bribe, and in expectation the bribe is equal to the expected difference between the bids made by the bidders with the highest and second-highest valuations. With ex ante bribery, the number of bidders paying the bribe is determined by the realizations of the values, and the auctioneer's revenue is found by maximizing (7). For symmetric bidders, which method generates greater profit for the auctioneer depends ultimately on the distribution of valuations and the number of bidders.

To see that ex ante bribery can be more profitable for the auctioneer than ex post bribery ${ }^{(10)}$ consider the power distribution $F(v)=v^{2}$. As argued above, any bidder with a valuation above $0.6^{1 / 2} \approx 0.775$ pays the bribe, and therefore as the number of bidders grows, so does the number of bidders who pay the bribe. Also, the optimal bribe is given by $\alpha^{*}=(2 n-2)\left(v^{* *}\right)^{3} /(6 n-3)$, which increases with the number of bidders. Consequently, with ex ante bribery and the power distribution, the auctioneer's revenue grows with the number of bidders. In contrast, with ex post bribery, the auctioneer's revenue 
falls as the number of bidders grows, since there the auctioneer's revenue is the expected difference between the two highest bids. As the number of bidders increases, the expected distance between the two highest bids shrinks. Straightforward calculations establish that when there are three or more bidders, ex ante bribery generates more revenue for the auctioneer than ex post bribery does. ${ }^{(1)}$

\section{NOTES}

1. Corruption can also arise through bidding rings, in which the bidders collude to increase their surplus from the seller. See, for example, Graham and Marshall (1987), McAfee and McMillan (1992), and Marshall and Marx (2002). Comte et al. (2000) link the bidding ring literature and the bribery literature with a model of ex post bribery in which the bidders use corruption to enforce collusive behavior.

2. Ingraham (2000) uses empirical methods to study bidder-auctioneer cheating in sealed-bid auctions. Based on the statistical properties of the bids, he develops a regression method for analyzing potential cheating of this type. He applies this regression specification to data from the New York City School Construction Authority auctions, and finds evidence that there is cheating between the auctioneer and the bidders.

3. I ignore issues related to the credibility of the auctioneer's promise, assuming instead that the promise is enforceable. Credibility might occur, for example, if the auctioneer makes this promise repeatedly in auctions over time, so that reputational concerns cause the auctioneer to keep the promise.

4. In the U.S., at least, many auctioneers are paid a commission based on the sales price. Such a payment scheme may reduce the auctioneer's incentives to solicit bribes, but that issue is left to future research. However, when a firm assigns the task of collecting bids to one of its employees, so that the employee is the auctioneer, that employee is rarely paid a commission.

5. The half-open interval $\left[0, v^{*}\right)$ is used because it is assumed that a bidder with valuation $v^{*}$, who is indifferent between paying the bribe and not paying it, elects to pay the bribe.

6. This is the result of the assumption that, if the bidder is indifferent, she prefers paying the bribe and the assumption that, corruption cannot be detected by law enforcement authorities and cannot be punished. The first assumption is due to simplification needs. The second is a strong assumption that I have made throughout the paper. Maybe a probability of detection by the seller can be introduced to the model as a future research. I think it is worth studying that issue in the future.

7. Maskin and Riley (2000) and Krishna (2002) both provide conditions under which the weak bidder bids more aggressively than the strong bidder.

8. In this case, a bribe paid by the strong bidder can be thought of as a payment for the right of first refusal, as in Grosskopf and Roth (2004) and Bikhchandani et al. (2004).

9. To see why there may not be a pure strategy equilibrium, suppose that the weak bidder's valuations are uniform on $[0,1]$ and the strong bidder's are uniform on $[0,2]$ with the bribe set so that the 
strong bidder pays the bribe whenever $v_{S} \geq 0.4$. The strong bidder's equilibrium bid function would have an upward discontinuous jump at $v_{S}=0.4$. In a pure strategy equilibrium the weak bidder would not make any bids in the gap left by the strong bidder's bid function, cannot have mass at the top of the gap, and cannot have mass at the bottom of the gap because then the strong bidder would want to change his bid function. But then a weak bidder with a valuation that places his bid at the top of the gap would have an incentive to reduce his bid, and therefore there cannot be a pure strategy equilibrium.

10. The uniform distribution provides an example in which ex post bribery generates more expected revenue for the auctioneer than ex ante bribery.

11. When there are three bidders, ex ante bribery generates expected revenue for the auctioneer of 0.149 , while ex post bribery generates expected revenue of 0.137 . As the number of bidders increases, expected revenue from ex ante bribery rises, while expected revenue from ex post bribery falls. When there are ten bidders, for example, expected revenue from ex ante bribery is 0.587 and from ex post bribery is 0.047 .

\section{REFERENCES}

Bikhchandani, S., Lippman, S., and Ryan, R. (2004). "On the Right-of-first-refusal," working paper, UCLA.

Burguet, R. and Che, Y.K. (2004). "Competitive Procurement with Corruption," Rand Journal of Economics, 35: 50-68.

Burguet, R. and Perry, M. (2000). "Bribery and Favoritism by Auctioneers in Sealed-Bid Auctions," working paper, Rutgers University, New Brunswick, NJ.

Celentani, M. and Ganuza, J.J. (2002). "Corruption and Competition in Procurement," European Economic Review, 46: 1273-1303.

Comte, O., Lambert-Mogliansky, A., and Verdier, T. (2000). "Corruption and Competition in Public Market Auctions," working paper, CERAS-ENPC, CNRS.

Cowan, R. and Century, D. (2002). Takedown: The Fall of the Last Mafia Empire. New York: G.P. Putnam's Sons.

Crowley, P. (2000). “Bid Scandal Bill in Trouble,” Cincinnati Enquirer, January 21.

Esö, P. and Schummer, J. (2004). "Bribing and Signaling in Second Price Auctions," Games and Economic Behavior, 47: 299-324.

Fibich, G., Gavious, A., and Sela, A. (2002). "Low and High Types in Asymmetric First-Price Auctions," Economics Letters, 75: 283-287.

----- (2004). "Revenue Equivalence in Asymmetric Auctions," Journal of Economic Theory, 115: 309-321. 
Graham, D.A. and Marshall, R.C. (1987). "Collusive Bidder Behavior at Single Object Second-Price and English Auctions," Journal of Political Economy, 95: 1217-1239.

Grosskopf, B. and Roth, A. (2004) "If You Were Offered the Right of First Refusal, Should You Accept? An Investigation of Contract Design," working paper, Texas A\&M University, College Station, TX.

Ingraham, A., (2000) “Testing for Cheating Between Bidders and Auctioneers in Sealed-Bid Auctions," working paper, University of Maryland, College Park, MD.

Krishna, V., (2002). Auction Theory. San Diego: Academic Press.

Lebrun, B. (1999) "First Price Auctions in the Asymmetric $N$ Bidder Case," International Economic Review, 40: 125-142.

Lengwiler, Y. and Wolfstetter, E. (2000). "Auctions and Corruption," working paper, HumboldtUniversitat zu Berlin, Germany.

Marshall, R.C. and Marx, L. (2002). "Bidder Collusion,” working paper, Penn State University, PA.

Maskin, E.S. and Riley, J.G. (2000). “Asymmetric Auctions,” Review of Economic Studies, 67: 413438.

McAfee, R.P. and McMillan, J. (1992). “Bidding Rings,” American Economic Review, 82: 579-599.

Menezes, F.M. and Monteiro, P.K. (2006). "Corruption and Auctions," Journal of Mathematical Economics, 42(1): 97-108.

Murphy, S.P. (1993). "Chelsea Businessman is Said to Allege Attempted Bribery," Boston Globe, September 22.

Myerson, R.B., (1981). “Optimal Auction Design,” Mathematical Operations Research 6: 58-73. 


\section{APPENDIX}

Proof of Lemma 2: Fix any equilibrium and consider the (right-continuous) cdf, $G_{i}(b)$, of the highest bid of bidders $j \neq i$. Also let $x_{i}(b)$ denote the probability of $i$ winning with bid $b$ against the rival bidders employing their equilibrium strategies. (Note that $x_{i}(b)$ may not equal $G_{i}(b)$ since a tie may arise at a mass point $b$.) Let $B_{c}$ be the set of $b$ 's for which $G$ is continuous, and let $B_{m}$ be the set of $b$ 's for which $G$ jumps. Then

$$
U_{i c}(v)=\int_{b \leq v, b \in B_{c}}(v-b) d G_{i}(b)+\sum_{b \leq v, b \in B_{m}}(v-b)\left[G_{i}\left(b_{+}\right)-G_{i}\left(b_{-}\right)\right]-\alpha .
$$

$U_{i c}(\cdot)$ is absolutely continuous and can be rewritten as

$$
U_{i c}(v)=\int_{v^{\prime}}^{v} G_{i}(s) d s+U_{i c}\left(v^{\prime}\right)
$$

for any $v^{\prime}$.

Now consider

$$
U_{i n}(v)=\sup _{b}(v-b) x_{i}(b) \text {. }
$$

It follows that

$$
U_{i n}(v)=\max _{b}(v-b) G_{i}(b)
$$

since $(v-b) G_{i}(b)$ is an upper envelope of $(v-b) x_{i}(b)$. One can check that $U_{i n}(v)$ is absolutely continuous, that the maximum is well defined (since an upper envelope is upper semi continuous and the choice can be bound to a compact set without loss of generality), and that $f(b, v):=(v-b) G_{i}(b)$ is differentiable in $v$ for every $b$ in the equilibrium support. Hence, one can invoke Theorem 2 of Milgrom and Segal to show that

$$
U_{i n}(v)=\int_{v^{\prime}}^{v} G_{i}\left(b^{*}(s)\right) d s+U_{i n}\left(v^{\prime}\right),
$$

for $b^{*}(s) \in \operatorname{argmax}_{b}(v-b) x_{i}(b)$.

It follows from (A1) and (A2) that

$$
U_{i c}(v)-U_{i n}(v)=\int_{v^{\prime}}^{v}\left[G_{i}(s)-G_{i}\left(b^{*}(s)\right)\right] d s+\left[U_{i c}\left(v^{\prime}\right)-U_{i n}\left(v^{\prime}\right)\right] .
$$

Since $b^{*}(s)<s$ for almost every $s$, it is clear from (A3) that, whenever $U_{i c}\left(v^{\prime}\right)-U_{i n}\left(v^{\prime}\right)>0$, it must 
be that $U_{i c}(v)-U_{i n}(v)>0$ for $v>v^{\prime}$, which proves that the equilibrium strategy must involve a cutoff strategy with some threshold $v_{i}^{*}$.

Proof of Theorem 1: By Lemma 2 every bidder uses a cutoff strategy, so there exist values $v_{1}{ }^{*}, \ldots, v_{n}{ }^{*}$ such that bidder $i$ pays the bribe if $v_{i} \geq v_{i}{ }^{*}$ and does not pay the bribe if $v_{i}<v_{i}{ }^{*}$. It remains to show that $v_{1}^{*}=\ldots=v_{n}^{*}=v^{*}$.

I first show that the lowest of the $n$ cutoff points is $v^{*}$. Suppose that player $i$ has the lowest threshold point, $v_{i}{ }^{*}$, and draws the valuation $v_{i}$. If he pays the bribe he bids his valuation, but if he does not pay the bribe, he bids the standard first-price equilibrium bid, since everyone below him also bids according to the standard first-price equilibrium bid function. Then, letting $H_{i}(\cdot)$ denote the cdf of the highest valuation of bidders $j \neq i$,

$$
U_{i c}\left(v_{i}^{*}\right)=\int_{0}^{v_{i}^{*}}\left(v_{i}^{*}-b_{1}(v)\right) d H_{i}(v)-\alpha
$$

and

$$
U_{i n}\left(v_{i}^{*}\right)=\left(v_{i}^{*}-b_{1}\left(v_{i}^{*}\right)\right) H_{i}\left(v_{i}^{*}\right) .
$$

Therefore

$$
U_{i c}\left(v_{i}^{*}\right)-U_{i n}\left(v_{i}^{*}\right)=\int_{0}^{v_{i}^{*}}\left(b_{1}\left(v_{i}^{*}\right)-b_{1}(v)\right) d H_{i}(v)-\alpha .
$$

The right-hand side is obviously increasing in $v_{i}^{*}$ (since the bid function increases) and it is equal to zero when $v_{i}^{*}=v^{*}$. Consequently, there is no equilibrium in which the lowest threshold point is below $v^{*}$.

I next show that the highest of the $n$ cutoff points is also $v^{*}$. Suppose that $i$ has the highest threshold value $v_{i}{ }^{*}>v^{*}$, and choose $v_{i} \in\left(v^{*}, v_{i}^{*}\right)$. It follows from equation (A3) in the proof of Lemma 2 that

$$
U_{i c}\left(v_{i}\right)-U_{i n}\left(v_{i}\right)=\int_{v^{*}}^{v_{i}}\left[G_{i}(s)-G_{i}\left(b^{*}(s)\right)\right] d s+\left[U_{i c}\left(v^{*}\right)-U_{i n}\left(v^{*}\right)\right] .
$$

By (A4), $U_{i c}\left(v^{*}\right)-U_{i n}\left(v^{*}\right)=0$. The integral in (A5) is positive for $v_{i}>v^{*}$, since $b^{*}(s)<s$ for almost all $s$. Consequently, bidder $i$ wants to pay the bribe when he draws the valuation $v_{i}<v_{i}^{*}$, which is a contradiction. 
